\title{
Peripheral Facial Palsy in Adult Von Recklinghausen Neurofibromatosis
}

\author{
Salem Bouomrani ${ }^{1,2 *}$, Wided Letaïef ${ }^{2,3}$, Ines Lamloum ${ }^{1,2}$, Rim Mesfar ${ }^{1,2}$ \\ ${ }^{l}$ Department of Internal medicine, Military Hospital of Gabes, Gabes 6000, Tunisia \\ ${ }^{2}$ Sfax Faculty of Medicine, University of Sfax, Sfax 3029, Tunisia \\ ${ }^{3}$ Department of Obstetrics and Gynecology, Regional Hospital of Gabes, Mtorrech 6014, Tunisia
}

*Corresponding Author: Salem Bouomrani, Department of Internal medicine, Military Hospital of Gabes, Gabes 6000, Tunisia, Email: salembouomrani@yahoo.fr

\begin{abstract}
Introduction: Among the possible neurological manifestations during neurofibromatosis type 1 (NF1), peripheral facial paralysis (PFP) remains exceptional, classically affects the child, and often associated to malignant degeneration.
\end{abstract}

We are reporting an original observation of PFP revealing NF1 in adult subject.

Case report: A 35-year-old Tunisian male, with no notable pathological history, consulted for vertigo, gait and balance disorder, and left hypoacusis progressively evolved for a month, with recent onset for two days of minimal facial asymmetry noted by family members.

Somatic examination noted peripheral vestibular syndrome and facial asymmetry relevant to moderate left PFP. The skin examination noted the existence of multiple "café-au-lait" spots, freckles, and little skin neurofibromas in the abdomen and back.

Radiological investigations (CT and MRI) concluded to a large left acoustic neurinoma stage IV according to the Kaus classification. Ophthalmologic examination showed bilateral iris Lisch nodules. Thus, the diagnosis of an NF1 complicated by a large left acoustic neurinoma causing an ipsilateral PFP was retained and patient was transferred to the department of Neurosurgery for adequate treatment.

Conclusion: PFP is an exceptional neurologic complication of NF1, unusual, and often overlooked by clinicians. As rare as it is, this manifestation of NF1 deserves to be known because its appearance often announces malignant degeneration.

Keywords: Peripheral facial palsy, Von Recklinghausen's disease, neurofibromatosis type 1, Phacomatosis, Facial paralysis, Acoustic neurinoma.

\section{INTRODUCTION}

Von Recklinghausen's disease (VRH) or neurofibromatosis type 1 (NF1) is a rare phacomatosis caused by autosomal dominant mutation affecting the neurofibromatosis gene located on chromosome 17 (17q11.2.) and with a prevalence of 0.02 to $0.03 \%$ [1,2].

Thus mutated fibromine would be unable, as a tumor suppressor, to control the maturation and proliferation of glial and neuronal cells, which explains the frequent development of neurological tumors (glioma, neuroma, and neurofibroma), which are the main signs of this disease [1-3].
Other clinical manifestations may be associated with these neurological tumors: cutaneous, bone, endocrine, cardiac, vascular, and ocular involvement signing the systemic nature of this disease and making its diagnosis sometimes a real challenge for the clinician $[2,4]$.

Among the possible neurological manifestations during this phacomatosis, peripheral facial paralysis remains exceptional, classically affects the child, and often associated to degeneration with the development of malignant tumors of the nerve sheaths [5-7].

We are reporting an original observation of PFP revealing VRH in adult subject. 


\section{CASE Report}

A 35-year-old Tunisian male, with no notable pathological history, consulted for vertigo, gait and balance disorder and left hypoacusis. These symptoms had progressively evolved for almost a month, with recent onset for two days of minimal facial asymmetry noted by family members.

Somatic examination noted peripheral vestibular syndrome and facial asymmetry relevant to left peripheral facial paralysis. The patient was otherwise well-conscious and oriented, apyretic, with stable hemodynamic and respiratory status. No peripheral lymphadenopathy, motor or sensory deficit of the limbs, or meningeal syndrome were noted. The skin examination noted the existence of multiple "café-au-lait" spots, freckles, and little skin neurofibromas in the abdomen and back (Fig.1).

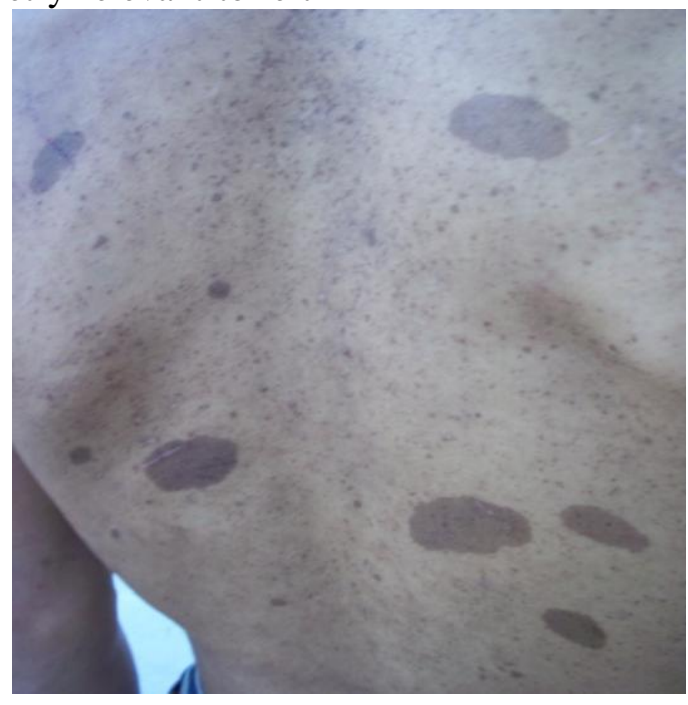

Fig.1: multiple “café-au-lait” spots, freckles and little skin neurofibromas in the back.

Biological tests, electrocardiogram, and chest Xray were without abnormalities.

The cerebral CT concluded to a tumor process of the left cerebellopontine angle. Cerebral MRI confirmed these findings by showing a left large cerebellopontine angle tumor with spontaneous isosignal on T1-weighted sequences (Fig.2), hypersignal on $\mathrm{T} 2$-weihted sequences, and a strongly enhancement after injection of contrast product (Fig.3). The tridimetional reconstruction concluded that this tumor process corresponded to a large neuroma of the left acoustic nerve stage IV according to the Kaus classification with intra- and extra- canal extension (Fig.4). The rest of the radiological investigations (medullary MRI, abdominal ultrasound, and ultrasound of the soft parts of the thighs) showed multiple neuromas and neurofibromas.

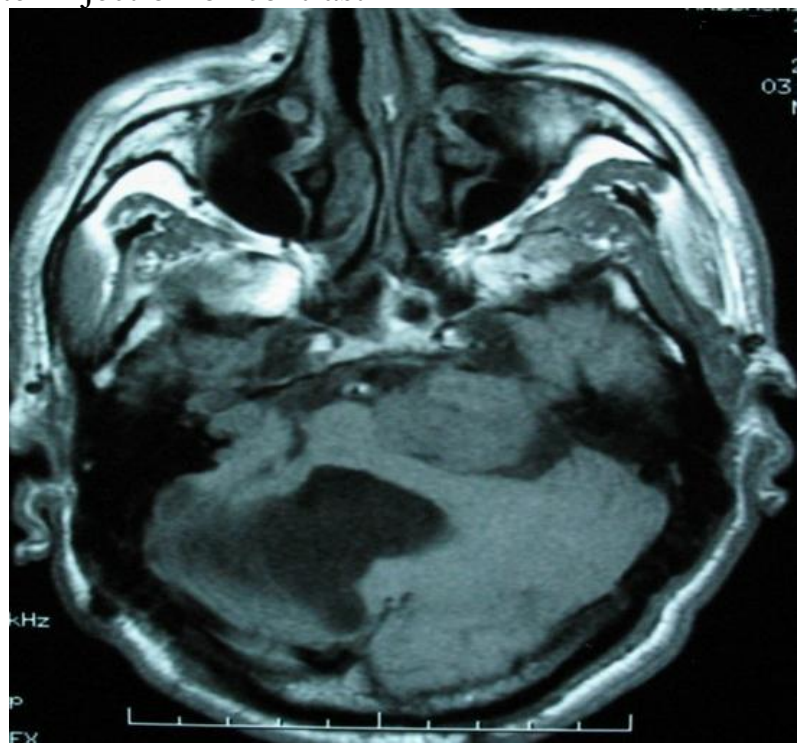

Fig2. T1-weighted axial brain MRI without injection of contrast product: left cerebellopontine angle tumoral process with spontaneous isosignal. 


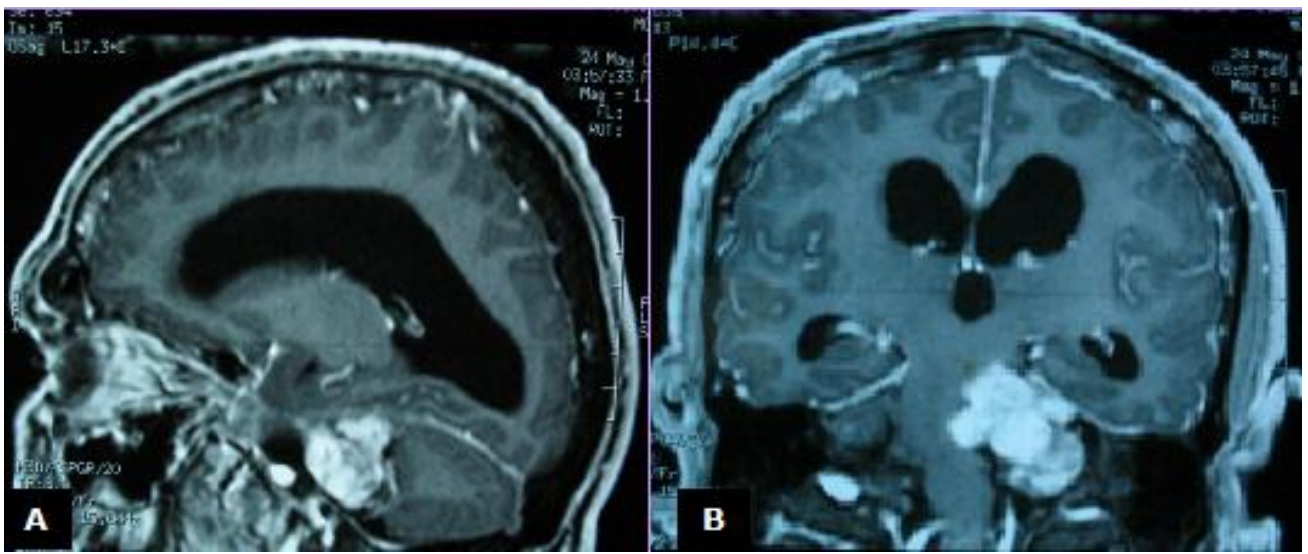

Fig3. Tl-weighted sagittal (A) and coronal (B) brain MRI with injection of contrast product: left cerebellopontine angle tumoral process with important enhancement.

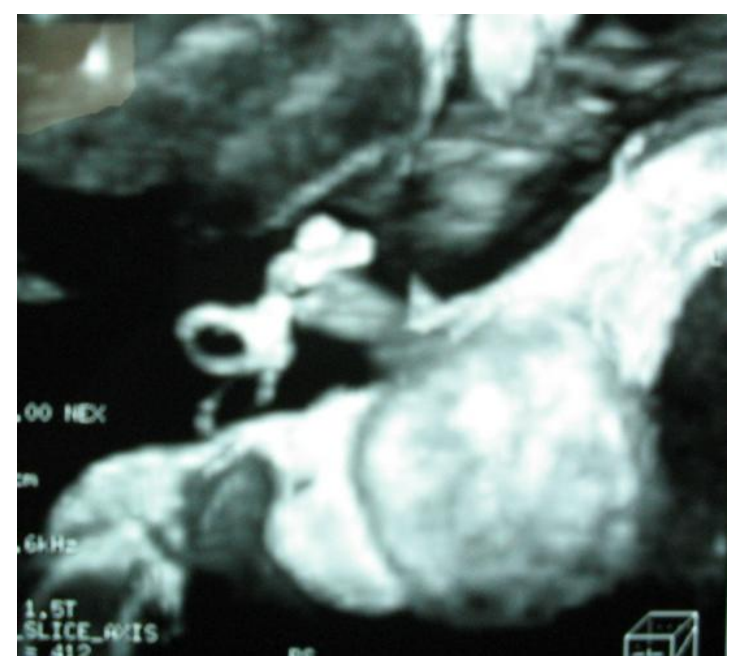

Fig4. T2-weighted cerebral MRI in oblique reconstruction: Large left acoustic neuroma with intra-and extracanal extension.

The specialized ophthalmologic examination showed bilateral iris Lisch nodules.

Thus, the diagnosis of NF1 (according to the National Institutes of Health criteria for neurofibromatosis diagnosis, 1988) complicated by a large left acoustic neurinoma causing an ipsilateral PFP was retained. The patient was transferred to the department of Neurosurgery for adequate treatment.

\section{DISCUSSION}

Neurological complications are not uncommon during NF1; indeed in the nationwide Japanese study of 3,530 patients with NF1, neurologic complications were noted in $38.1 \%$ of patients [8]. These complications mainly affect the central nervous system while peripheral neuropathies are much rarer $[5,6,8,9]$. Clinical presentation of these central complications may be: epilepsy, cerebral infarction, visual disturbances, behavioral disorders, cranial nerve involvement, hydrocephalus, intracranial hypertension, and neuroendocrine signs such as precocious puberty $[5,6,9]$. These manifestations are classically related to intracranial gliomas, meningiomas or neuromas $[5,6,9]$.

The peripheral neurological manifestations of NF1 can be of the type of radiculopathy, mononeuritis, polyneuropathy, and multiplex mononeuritis [5] and are often related to peripheral nervous system tumours or more rarely secondary to the compression of the peripheral nerves by fibromas $[5,6,10]$.

Of all the possible neurological complications of NF1, PFP remains exceptional and unusual $[5,10,11]$. Indeed, in the series of Creange A et al of 158 patients with NF1 including 87 with neurological complications, the PFP was noted in only one case: $0.6 \%$ of NF1 and $1.14 \%$ of the neurological manifestations of the NF1 [5].

PFP during NF1 is most often caused by compression of the nerve VII in its extra cranial portion by:

- Acoustic neuroma [11], particularly in the case of very large neuromas $[11,12]$. PFP secondary 
to acoustic neuroma is classically very minimal and of late onset [12],

- Malignant degeneration, with development of malignant tumors of peripheral nerve sheaths (malignant schwannoma), which is seen in $10 \%$ of NF1 cases [7]. These tumors may sit at the level of the parotid gland [14] or at the anterior skull base [14].

- Tumors of the facial nerve itself are exceptional during NF1 [13].

Acoustic neuroma/neurinoma also called vestibular schwannoma, is very rare during NF1 compared with other phacomatosis, particularly NF2 [10,12]. It is typically unilateral $(24 \%$ of unilateral acoustic neuromas are related to NF1), preferentially affects the child, and is often associated with other intracranial tumors of NF1 [10-12]. Bilateral forms can however be noted [11].

The treatment of these neuromas is mainly surgical, especially for large tumors; Stereotactic radiotherapy may also be considered [12].

\section{Conclusion}

Peripheral facial palsy is an exceptional neurologic complication of NF1, unusual, and often overlooked by clinicians. It may be related to an acoustic neuroma or malignant tumors of the nerve sheaths in the parotid or the anterior skull base.

As rare as it is, this manifestation of NF1 deserves to be known by clinicians because its appearance often announces malignant degeneration (malignant schwannoma).

\section{REFERENCES}

[1] Ventéjou S, Leducq S, Maruani A, Georgescou G, Samimi M. Neurofibromatose de type 1 . Presse Med. 2018;47(7-8 Pt 1):711-712.

[2] Cimino PJ, Gutmann DH. Neurofibromatosis type 1. Handb Clin Neurol. 2018;148:799-811.

[3] Sabol Z, Kipke-Sabol L. Neurofibromatosis type 1 (von Recklinghausen's disease or peripheral neurofibromatosis): from phenotype to gene. Lijec Vjesn. 2005;127(11-12):303-11.

[4] Bouomrani S, Regaïeg N, Belgacem N, Trabelsi S, Lassoued N, Baili H. Latent Autoimmune
Diabetes in Adults Associated with Von Recklinghausen's Disease (Neurofibromatosis Type 1). Journal of Autoimmune Diseases and Rheumatology. 2018;6:1-4.

[5] Créange A, Zeller J, Rostaing-Rigattieri S, Brugières $\mathrm{P}$, Degos JD, Revuz $\mathrm{J}$, et al. Neurological complications of neurofibromatosis type 1 in adulthood. Brain. 1999;122 ( Pt 3):47381.

[6] Hsieh HY, Wu T, Wang CJ, Chin SC, Chen YR. Neurological complications involving the central nervous system in neurofibromatosis type 1. Acta Neurol Taiwan. 2007;16(2):68-73.

[7] Valeyrie-Allanore L, Ismaïli N, Bastuji-Garin $\mathrm{S}$, Zeller J, Wechsler J, Revuz J, et al. Symptoms associated with malignancy of peripheral nerve sheath tumours: a retrospective study of 69 patients with neurofibromatosis 1 . Br J Dermatol. 2005;153(1):79-82.

[8] Yoshida Y, Ehara Y, Koga M, Imafuku S, Yamamoto O. Epidemiological Analysis of Major Complications Requiring Medical Intervention in Patients with Neurofibromatosis 1. Acta Derm Venereol. 2018;98(8):753-756.

[9] Guillamo JS, Créange A, Kalifa C, Grill J, Rodriguez D, Doz F, et al. Prognostic factors of CNS tumours in Neurofibromatosis 1 (NF1): a retrospective study of 104 patients. Brain. 2003 Jan;126(Pt 1):152-60.

[10] Huq A, Kentwell M, Tirimacco A, Rossini J, Rawlings L, Winship I. Vestibular schwannoma in a patient with neurofibromatosis type 1: clinical report and literature review. Fam Cancer. 2015;14(1):157-60.

[11] Krämer U. Symptoms of Recklinghausen's disease in the field of ENT medicine. Laryngol Rhinol Otol (Stuttg). 1987;66(5):275-9.

[12] Greene J, Al-Dhahir MA. Acoustic Neuroma (Vestibular Schwannoma). SourceStatPearls [Internet]. Treasure Island (FL): StatPearls Publishing; 2018-.2018 Nov 25.

[13] Başaran B, Orhan KS, Polat B, Mete O, Başerer N. Malignant peripheral nerve sheath tumor in the parotid gland developed on the basis of neurofibromatosis type 1. Kulak Burun Bogaz Ihtis Derg. 2011;21(4):220-4.

[14] Ueda R, Saito R, Horiguchi T, Nakamura Y, Ichikizaki K. Malignant peripheral nerve sheath tumor in the anterior skull base associated with neurofibromatosis type 1--case report. Neurol Med Chir (Tokyo). 2004;44(1):38-42.

Citation: Salem Bouomranil, et al. Peripheral Facial Palsy in Adult Von Recklinghausen Neurofibromatosis. ARC Journal of Neuroscience. 2019; 4(2):4-7. doi: dx.doi.org/10.20431/2456-057X 0402002.

Copyright: (C) 2019 Authors. This is an open-access article distributed under the terms of the Creative Commons Attribution License, which permits unrestricted use, distribution, and reproduction in any medium, provided the original author and source are credited. 